
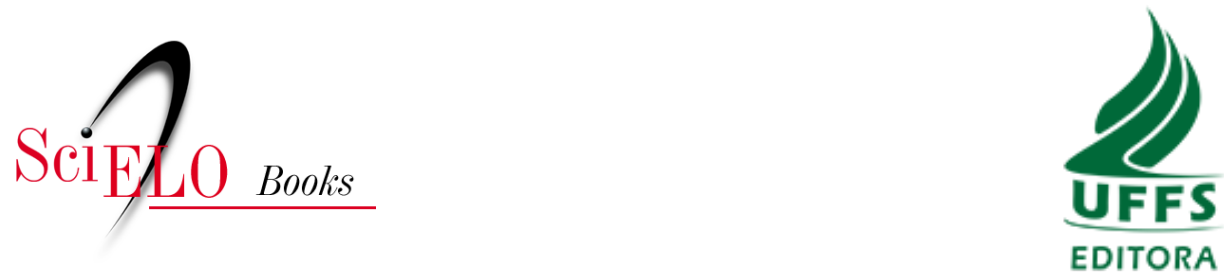

Parte V - Desenvolvimento e novas tecnologias produtivas e sociais

\title{
Capítulo 2 - Estudo bibliométrico da produção científica sobre terceiro setor, entre 2010 a 2016
}

\author{
Flávia Regina Schirmanm \\ Cleomar Minetto \\ Eliseu Champe da Silva \\ Luciana Scherer \\ Louise de Lira Roedel Botelho
}

\section{SciELO Books / SciELO Livros / SciELO Libros}

SCHIRMANM, F.R., MINETTO, C., SILVA, E.C., SCHERER, L., and BOTELHO, L.L.R. Estudo bibliométrico da produção científica sobre terceiro setor, entre 2010 a 2016. In: ROTTA, E., LAGO, I.C., JUSTEN, A.F., and SANTOS, M., eds. Conhecimento em rede: desenvolvimento, cooperação e integração regional em território de fronteira - Rede CIDIR: 10 anos [online]. Chapecó, SC: Editora UFFS, 2019, pp. 278292. ISBN: 978-65-5019-011-8.

https://doi.org/10.7476/9786586545432.0017.

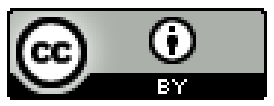

All the contents of this work, except where otherwise noted, is licensed under a Creative Commons Attribution 4.0 International license.

Todo o conteúdo deste trabalho, exceto quando houver ressalva, é publicado sob a licença Creative Commons Atribição 4.0.

Todo el contenido de esta obra, excepto donde se indique lo contrario, está bajo licencia de la licencia Creative Commons Reconocimento 4.0. 


\title{
ESTUDO BIBLIOMÉTRICO DA PRODUÇÃO CIENTÍFICA SOBRE TERCEIRO SETOR, ENTRE 2010 A 2016
}

\author{
Flávia Regina Schirmanm ${ }^{1}$ \\ Cleomar Minetto $^{2}$ \\ Eliseu Champe da Silva ${ }^{3}$ \\ Luciana Scherer ${ }^{4}$ \\ Louise de Lira Roedel Botelho ${ }^{5}$
}

1 Administradora (UFFS). Contato: flavia.itcees@gmail.com

2 Administrador (UFFS). Contato: cleomar.itcees@gmail.com

3 Administrador (UFFS). Mestrando em Desenvolvimento Rural - Bolsista Capes - Universidade Federal do Rio Grande do Sul. Contato: eliseu.itcees@gmail.com

4 Doutoranda em Desenvolvimento Regional (UNIJUÍ). Mestra em Ciências Sociais, Administradora (UFRGS). Professora no Curso de Administração da URI Cerro Largo. Contato: lucianascherer@ yahoo.com.br

5 Pós-Doutora, Doutora e Mestra em Engenharia e Gestão do Conhecimento (UFSC). Professora no Curso de Administração e no Mestrado em Desenvolvimento e Políticas Públicas da UFFS. Contato: louisebotelho@uffs.edu.br 


\section{INTRODUÇÃO}

Termos como responsabilidade social, solidariedade e generosidade têm ganhado cada vez mais espaço na sociedade brasileira, pois trazem à tona conceitos que até então ficaram submersos em algumas áreas do conhecimento, como as ciências humanas e sociais. $\mathrm{Na}$ atualidade, tais termos têm sido aos poucos inseridos em outras áreas do saber, como nas ciências sociais aplicadas, e muito disso se deve aos estudiosos destas áreas.

Na busca pelo entendimento da expressão “terceiro setor", se faz necessário o aprimoramento de questionamentos, que possuem origem em tentativas da compreensão da sociedade e suas diferentes demandas. Por isso, a produção científica se estabelece como ferramenta de análise, aprimorando, assim, conceitos ligados à sociedade, no intuito de compreender e discutir com mais intensidade as diferentes temáticas, dentre elas a questão do terceiro setor. De forma geral, diferentes autores acabaram por realizar esforços para construir a compreensão de tal temática, a exemplo de Fernandes (1997), Laville (2000) e Singer (2009).

Para uma melhor compreensão do assunto a ser estudado serão apresentados conceitos básicos sobre terceiro setor: "é constituído por organizações sem fins lucrativos e não governamentais, que tem como objetivo gerar serviços de caráter público" (FILANTROPIA, 2016). O primeiro setor é compreendido como sendo o Governo, seguido pelo segundo setor que é o Mercado privado. $\mathrm{O}$ terceiro setor tem se expandido pelo fato de organizações se destacarem como sendo deste setor, uma vez que fazem o intermédio entre o Estado e o mercado atuante, verificando uma posição de interesses da sociedade. Nesse contexto estão incluídas organizações não governamentais (ONGs), que se destacam pela luta de direitos humanos, possuindo, assim, fundações e associações mais identificadas como filantropia (caridade) empresarial e com movimentos de base (ARRUDA, 2003).

O estudo que constitui este capítulo teve como objetivo principal realizar um levantamento bibliométrico da produção científica sobre terceiro setor no período de 2010 a 2016 na base de dados da Scientific Periodicals Electronic Library (SPELL). O espaço temporal foi definido pela expressiva quantidade de estudos encontrados sobre esses temas nessa base de dados. 


\section{METODOLOGIA}

O levantamento bibliométrico, segundo Da Fonseca (1973), é caracterizado por "uma análise em um Portfólio Bibliográfico aplicando métodos estatísticos e matemáticos". O autor ainda salienta que com essa metodologia bibliométrica ocorre uma ampla disseminação de conhecimentos.

Para Macias-Chapula (1998), “a bibliométria é o estudo dos aspectos quantitativos da produção, disseminação e uso da informação registrada”. Dessa forma, este estudo investigou e analisou estudos sobre o terceiro setor, utilizando dados do SPELL, momento pelo qual foram utilizados descritores ${ }^{6}$ para busca de estudos científicos.

Esta pesquisa é de natureza descritiva, que, de acordo com Vergara (2000), "expõe as características de determinada população ou fenômeno, estabelece correlações entre variáveis e define sua natureza”. Quanto à abordagem, a pesquisa é classificada pela análise quantitativa, definida por Richardson (1989) como sendo "um método que se caracteriza pelo emprego da quantificação, tanto nas modalidades de coleta de informações, quanto no tratamento dessas através de técnicas estatísticas, desde as mais simples até as mais complexas".

O método foi composto inicialmente por três etapas: primeira (identificação do tema; identificação do problema; formulação da pergunta de pesquisa; delineação da estratégia de busca; delineação dos descritores; definição da base de dados); segunda (identificados os critérios de inclusão; identificados os critérios de exclusão); terceira etapa (identificação dos estudos pré-selecionados; identificação dos estudos selecionados).

\section{Terceiro Setor no Brasil}

Para Alves (2002), nos meados de 1820 a 1830, as ações sociais eram exclusivas da igreja católica e, portanto, não cabia ao governo atuar sobre tais causas. Um cenário social ganhou forma e começou a estabelecer-se a partir da Revolução da década de 30 até a década 60, quando foi criada a primeira lei brasileira, sendo criado o Conselho Nacional do Serviço Social.

6 Descritores são palavras-chave, sendo utilizadas na base de dados, de forma a encontrar artigos relacionados com os descritores. 
Hoje o terceiro setor ocupa uma posição de destaque na sociedade brasileira, atuando com políticas de apoio. Para Alves (2002), o terceiro setor é um termo "guarda-chuvas" capaz de incluir vários tipos de organizações e no qual se inclui também diferente marco teórico.

“A expressão 'Terceiro Setor' começou a ser usada nos anos 70 nos EUA para identificar um setor da sociedade no qual atuam organizações sem fins lucrativos, voltadas para a produção ou a distribuição de bens e serviços públicos" (FERNANDES, 1997).

A partir do século XX, as organizações sem fim lucrativo, cujo objetivo propunha combater a miséria e a pobreza, aumentaram. E isso se explica pelo aumento da "influência do Estado na gestão administrativa e no financiamento das organizações assistenciais e filantrópica” (BRITO, 2008).

Brito (2008) ressalva que a renovação das organizações de terceiro setor teria ocorrido após os anos do ciclo virtuoso do fordismo e foi entendida como uma evolução do agir coletivo da sociedade, fundamentada na cooperação social.

[...] A ideia de Terceiro Setor está muitas vezes ligada à ideia de atuação de um terceiro ator na sociedade. Por vezes, os indivíduos desta sociedade se constituem neste terceiro ator a fim de se posicionarem entre o setor mercantil e público, unindo-se por um ideal de utilidade coletiva ou um senso de utilidade social" (LAVILLE s/p apud FRANÇA FILHO, 2002).

O terceiro setor surge como um instituto que traz uma nova e grande promessa para a sociedade. Essa promessa seria gerada pela esperança acendida por meio de atividades geridas por organizações que trabalham para a renovação do espaço público, o resgate da solidariedade e da cidadania, a humanização do capitalismo e a diminuição da pobreza (FALCONER, 1999).

Pode-se dizer que a atuação do primeiro e segundo setor seria complementada por esse terceiro ator, que possuiria a racionalidade da compreensão e necessidade de diversos grupos da sociedade. Seria, então, o terceiro setor um elemento complementar que viria a preencher as lacunas deixadas tanto pelo mercado como pelo Estado (BRITO, 2008). Ele é constituído por organizações não governamentais sem fins lucrativos, especialmente as entidades assistenciais, que desenvolvem um trabalho social junto à população "excluída”. O terceiro setor engloba basicamente entidades sociais (FILOMENO, 1997). 
Segundo Bento (2010), o terceiro setor cresceu a tal ponto que as entidades se tornaram concorrentes na busca de recursos, seja do Estado ou do setor privado. Já os espaços deixados pelo Estado (primeiro setor) e pelo setor privado, que atua na comercialização de bens e serviços (segundo setor), através de associações civis e fundações de direito privado, mobilizadas por iniciativas de desenvolvimento social, são organizações de natureza "privada" que não possuem finalidade de lucro, possuem objetivos sociais ou públicos (PAES, 2003).

Nesse conceito surgem os movimentos sociais, enfatizando as organizações sociais e valorizando as pessoas (SERVA, 1997). As ONGs são organizações não governamentais, que tiveram início nos anos 60 , década em que se observa a vasta criação de organizações que não são nem consideradas estatais e nem privadas.

\section{As Incubadoras Tecnológicas de Cooperativas Populares e a geração de conhecimento do (e para) Terceiro Setor}

As Incubadoras Tecnológicas de Cooperativas Populares (ITCPs) têm objetivo de promover desenvolvimento sustentável através de atividades de extensão para empreendimentos de economia solidária, o que agrega o terceiro setor da economia. As incubadoras tiveram seu início no ano de 1995, por meio de uma demanda de um grupo da sociedade civil denominado Comitê de Entidades no Combate à Fome e pela Vida. Essa organização, liderada pelo sociólogo Herbert de Souza, se estruturou junto à Coordenação dos Programas de Pós-Graduação em Engenharia da Universidade Federal do Rio de Janeiro (COPPE/UFRJ), a fim de construir uma metodologia de incubação para o cooperativismo popular e difundi-la por outras universidades do país (REZENDE; BOEIRA, 2014). Em 1998, 14 ITCPs resolveram organizar-se em rede com o objetivo de instituir um processo intenso de troca de conhecimentos e colaboração mútua (SINGER, 2000, p.130). Atualmente houve uma ampliação da Rede de ITCPs e 54 incubadoras fazem parte dela.

As ITCPs buscam articular multidisciplinarmente áreas de conhecimento de universidades brasileiras com grupos populares interessados em gerar trabalho e renda, visando contribuir na formação de cooperativas populares e ou empresas autogestionárias. Sua atuação se dá em um duplo sentido, na formação dos estudantes, por meio da vinculação do ensino, da pesquisa e da extensão, e 
na geração de trabalho e renda (GUERRA, 2008). O seu trabalho está voltado para o processo educativo por intermédio da cooperação e da autogestão, constituindo-se como projetos, programas ou órgãos das universidades.

Para efetivar a atuação das ITCPs com os grupos beneficiários, nesse caso os empreendimentos incubados, há o processo chamado incubação. Geralmente envolve desde o primeiro contato, sua aceitação, formação, assessoria, acompanhamento até sua saída da ITCP (desincubação). A metodologia de incubação pode ser vista como um processo educativo (PEREIRA, 2007), dialógico, participativo, emancipatório ou de gestão e assessoramento (BOTELHO et al., 2013).

A metodologia de incubação é embasada, fundamentalmente, por dois eixos de atuação: um relacionado aos princípios da cooperação e autogestão e o desenvolvimento da capacidade emancipatória dos incubados; o segundo eixo é relacionado à viabilidade econômica composto por administração, produção e comercialização, inserção produtiva, educação e capacitação profissional. Carvalho e Cançado (2009) afirmam que o processo de incubação busca promover a autossustentabilidade dessas organizações. Torna-se um instrumento educativo/pedagógico desenvolvedor de diversos tipos de conhecimentos, dentre eles a gestão e o terceiro setor.

As incubadoras são, em sua maioria, órgãos ligados às diversas universidades do país, que têm por objetivo utilizar os recursos humanos e os conhecimentos da universidade na formação, qualificação e assessoria de trabalhadores para a construção de atividades autogestionárias, visando sua inclusão no mercado de trabalho (GUIMARÃES, 1999).

Para os pesquisadores, as ITCPs são propícias ao desenvolvimento de modelos de gestão alternativos, pois: (i) desenvolvem projetos de pesquisas e estudos relacionados à Economia Solidária; (ii) possuem maior parte do conteúdo dos cursos de formação técnica são referentes às atividades administrativas; (iii) criam seus próprios materiais didáticos utilizados nos cursos de formação; (iv) apresentam profissionais capacitados nas atividades de incubação (docentes, discentes, pesquisadores e técnicos); e (v) apresentam diversas experiências nas incubações de empreendimentos solidários nos moldes autogestionários.

Nesse sentido, as ITCPs formam um ambiente propício para o estudo de práticas de gestão social e para o desenvolvimento do terceiro setor. 


\section{ANÁLISES DOS RESULTADOS}

Após percorridas as etapas descritas na metodologia - $1^{\text {a }}$ (identificação do tema; identificação do problema; formulação da pergunta de pesquisa; delineação da estratégia de busca; delineação dos descritores; definição da base de dados); $2^{a}$ (identificados os critérios de inclusão; identificados os critérios de exclusão); $3^{a}$ (identificação dos estudos pré-selecionados; identificação dos estudos selecionados) -, identificaram-se 12 estudos publicados entre o período de 2010 e 2016, do qual apenas em 2015 e 2016 não houve nenhum artigo publicado. A Tabela 1 apresenta os 12 artigos, com seus títulos, anos de publicação e autores.

Tabela 1 - Artigos identificados

\begin{tabular}{l|l|l}
\hline Título do Artigo & Ano & Autor/ Autores \\
\hline $\begin{array}{l}\text { Avaliação de Atividades no Terceiro Setor de } \\
\text { Belo Horizonte: da racionalidade subjacente } \\
\text { às influências institucionais }\end{array}$ & 2011 & $\begin{array}{l}\text { Carlos Eduardo Guerra Silva } \\
\text { Afrânio Carvalho Aguiar }\end{array}$ \\
\hline $\begin{array}{l}\text { Avaliação de projetos sociais em ONGs } \\
\text { da Grande Florianópolis: um estudo sobre } \\
\text { modelos relacionados ao foco de atuação }\end{array}$ & 2011 & $\begin{array}{l}\text { Jairo José Assumpção; } \\
\text { Lucila Maria de Souza Campos }\end{array}$ \\
\hline $\begin{array}{l}\text { Gestão, legislação e fontes de recursos no } \\
\text { terceiro setor brasileiro: uma perspectiva } \\
\text { histórica. }\end{array}$ & 2010 & Carlos Eduardo Guerra Silva \\
\hline $\begin{array}{l}\text { Participação em redes transnacionais e a } \\
\text { formulação de políticas locais em mudanças } \\
\text { climáticas: o caso de Palmas }\end{array}$ & 2013 & $\begin{array}{l}\text { Lia de Azevedo Almeida; } \\
\text { Mônica Aparecida da Rocha Silva; } \\
\text { Ronaldo Augusto Campos Pessoa }\end{array}$ \\
\hline $\begin{array}{l}\text { Abordagens teóricas da Gestão Social: uma } \\
\text { análise de citações exploratória }\end{array}$ & 2014 & $\begin{array}{l}\text { Miguel Rivera Peres Jr. } \\
\text { José Roberto Pereira }\end{array}$ \\
\hline $\begin{array}{l}\text { Atuação de bancos estrangeiros no Brasil: } \\
\text { mercados de crédito e derivativos de 2005 a }\end{array}$ & 2014 & $\begin{array}{l}\text { Raquel de Freitas Oliveira } \\
\text { Rafael Felipe Schiozer } \\
\text { Sérgio Leão }\end{array}$ \\
\hline $\begin{array}{l}\text { Conteúdo estratégico em organizações do } \\
\text { Terceiro Setor: possibilidades e implicações } \\
\text { de pesquisa no campo social }\end{array}$ & 2010 & $\begin{array}{l}\text { Augusto Cesar Marins Machado } \\
\text { Sergio Bulgacov }\end{array}$ \\
\hline $\begin{array}{l}\text { Estratégias de sobrevivência e avanço numa } \\
\text { organização do terceiro setor: o papel dos } \\
\text { capacitadores do conhecimento na Junior } \\
\text { Achievementde Minas Gerais }\end{array}$ & 2014 & $\begin{array}{l}\text { Carlos Ronan de Alvim Braga } \\
\text { Maria Celeste Vasconcelos } \\
\text { Emerson AntonioMaccari } \\
\text { Jorge Tadeu de Ramos Neves }\end{array}$ \\
\hline
\end{tabular}




\begin{tabular}{l|l|l}
\hline $\begin{array}{l}\text { Gestão de mudanças nas organizações do } \\
\text { terceiro setor: o desafio da sustentabilidade } \\
\text { financeira }\end{array}$ & 2012 & $\begin{array}{l}\text { Tobias Coutinho Parente } \\
\text { Gabriela Pellegrini Tiscoski } \\
\text { Talita Rosolen } \\
\text { Matheus RoquetteFerrato da Silva } \\
\text { Ana Carolina Abreu de Campos } \\
\text { Douglas Aparecido Sakamuto }\end{array}$ \\
\hline $\begin{array}{l}\text { Performance no terceiro setor uma } \\
\text { abordagem de accountability: estudo de caso } \\
\text { em uma Organização Não Governamental } \\
\text { Brasileira }\end{array}$ & 2010 & $\begin{array}{l}\text { June Alisson Westarb Cruz } \\
\text { Carlos Olavo Quandt } \\
\text { Tomás Sparano Martins } \\
\text { Wesley Vieira da Silva }\end{array}$ \\
\hline $\begin{array}{l}\text { Redes organizacionais: perspectiva para } \\
\text { sustentabilidade de uma ONG }\end{array}$ & 2010 & $\begin{array}{l}\text { Edileusa Godoi-de-Sousa; } \\
\text { Valdir Machado Valadão Jr. }\end{array}$ \\
\hline $\begin{array}{l}\text { Terceirização na gestão da manutenção: } \\
\text { estudo de caso de uma mineradora }\end{array}$ & 2013 & $\begin{array}{l}\text { Luiz Alex Silva Saraiva; } \\
\text { Ronaldo Eurípedes das Mercês }\end{array}$ \\
\hline
\end{tabular}

Fonte: Elaborada pelos autores.

Como se verifica no Gráfico 1, o ano iniciante da investigação é o que tem mais representação nas publicações.

Gráfico 1 - Ano de publicações do tema terceiro setor

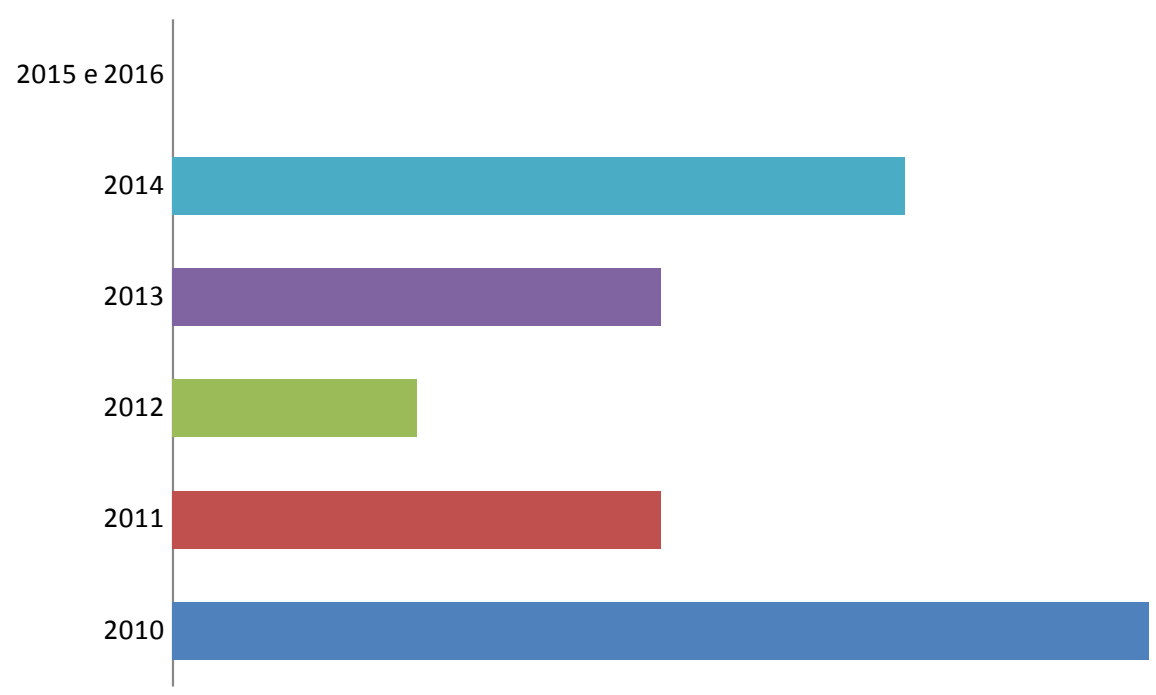

Fonte: Elaborado pelos autores.

O ano de 2010 destaca-se como o ano com mais publicações sobre terceiro setor, seguido por 2014. Chama a atenção o fato de não haver nenhuma publicação nos anos de 2015 e 2016. 
Outro ponto de análise é sobre os autores mais frequentes entre as 12 publicações estudadas entre os anos de 2010 a 2016 na base de dados da SPELL. No que diz respeito a autores com maiores repetições, podemos verificar que apenas um autor frequente - Carlos Eduardo Guerra Silva - é repetido nas 12 publicações sobre o tema terceiro setor. Essa análise é aceitável pelo baixo número de artigos deste tema bastante amplo na área acadêmica; outros 31 autores foram encontrados nestas publicações.

Em decorrência da análise dos autores que mais publicaram sobre terceiro setor, foi analisada a evolução da quantidade de autores por publicação entre os anos de 2010 a 2016 na SPELL. Destacam-se os artigos "Gestão de Mudanças nas Organizações do Terceiro Setor: o Desafio da Sustentabilidade Financeira”, o qual possui seis autores, e "Estratégias de Sobrevivência e Avanço numa Organização do Terceiro Setor: o Papel dos Capacitores do Conhecimento na Junior Achievement de Minas Gerais", com cinco autores. A incidência maior em relação ao número de autores por artigo foi de dois a três autores por publicação.

O estudo concentra-se, ainda, em investigar quais foram os periódicos mais encontrados nas publicações referentes ao tema terceiro setor. Os destaques são para os periódicos Revista de Administração Pública, com três artigos, e a Revista da Administração da UNIMEP, com duas publicações. A Revista de Administração Pública ocupa grande destaque nesse campo, pois ela busca transformar as relações da sociedade, apresentando embasamento teórico aos leitores, junto com debates que proporcionam uma ampla discussão acerca de assuntos presentes em nosso meio (REVISTA DE ADMINISTRAÇÃO PÚBLICA, 2016). Já a Revista da Administração da UNIMEP tem como missão “contribuir para o aprimoramento e a disseminação dos conhecimentos em Administração por meio da publicação de trabalhos de pesquisa, análises teóricas e resenhas sobre ESTRATÉGIA, ORGANIZAÇÕES, MARKETING, GESTÃO DE PESSOAS, FINANÇAS, OPERAÇÕES E LOGÍSTICA” (RAU, 2016).

Ambas as revistas descritas possuem ligação com a Administração. Além de buscarem integrar uma sociedade em busca de novos conhecimentos, buscam também identificar pesquisadores para que eles possam contribuir com novas ideias e cenários teóricos, proporcionando à população o acesso a assuntos dos mais diversos contextos. 
Após a identificação dos periódicos mais frequentes, verificou-se a necessidade de apresentar o Qualis com maior incidência nesses periódicos, sendo identificada como o fator de impacto mais relevante. Esses dados podem ser visualizados na Tabela 2, apresentada a seguir.

Tabela 2 - Quantidade de artigos referente ao Qualis sobre o tema terceiro setor

\begin{tabular}{l|l}
\hline QUALIS DOS ARTIGOS & NÚMERO \\
\hline A2 & 4 \\
\hline B1 & 2 \\
\hline B2 & 6 \\
\hline
\end{tabular}

Fonte: Elaborada pelos autores.

O Qualis mais identificado foi o B2, seguido por A2 e B1. A Revista da Administração da UNIMEP está classificada como B2 no sistema Qualis/Capes. Já a Revista de Administração Pública, que foi o periódico com maior destaque entre os estudados no terceiro setor, possui Qualis A2.

Outro objetivo foi identificar a instituição de ensino dos autores. Como mostra a Tabela 3, destaca-se a Universidade Federal de Minas Gerais (UFMG), seguida pela Universidade Federal de São Paulo (USP) e Faculdade Paranaense (FAPAR).

Tabela 3 - Instituições de ensino dos autores

\begin{tabular}{l|l}
\hline AUTOR/ AUTORES & INSTITUIÇÃO \\
\hline $\begin{array}{l}\text { Carlos Eduardo Guerra Silva } \\
\text { Afrânio Carvalho Aguiar }\end{array}$ & UFMG \\
\hline $\begin{array}{l}\text { Jairo José Assumpção; } \\
\text { Lucila Maria de Souza Campos }\end{array}$ & $\begin{array}{l}\text { UNIVALI } \\
\text { UFSC }\end{array}$ \\
\hline Carlos Eduardo Guerra Filho & UFMG \\
\hline $\begin{array}{l}\text { Lia de Azevedo Almeida; } \\
\text { Mônica Aparecida da Rocha Silva; } \\
\text { Ronaldo Augusto Campos Pessoa }\end{array}$ & UFT \\
\hline $\begin{array}{l}\text { Miguel Rivera Peres Jr. } \\
\text { José Roberto Pereira }\end{array}$ & \\
\hline $\begin{array}{l}\text { Raquel de Freitas Oliveira } \\
\text { Rafael Felipe Schiozer } \\
\text { Sérgio Leão }\end{array}$ & IFMG \\
\hline
\end{tabular}




\begin{tabular}{l|l}
\hline $\begin{array}{l}\text { Augusto Cesar Marins Machado } \\
\text { Sergio Bulgacov }\end{array}$ & PUCPR \\
\hline $\begin{array}{l}\text { Carlos Ronan de Alvim Braga } \\
\text { Maria Celeste Reis Lobo Vasconcelos } \\
\text { Emerson AntonioMaccari } \\
\text { Jorge Tadeu de Ramos Neves }\end{array}$ & UFMG \\
\hline Tobias Coutinho Parente & \\
Gabriela Pellegrini Tiscoski & USP \\
Talita Rosolen & USP \\
Ana Carolina Abreu de Campos & UNICAMP \\
Douglas Aparecido Sakamuto & UNICAMP \\
\hline June Alisson Westarb Cruz & UNICAMP \\
Carlos Olavo Quandt & FAPAR \\
Tomás Sparano Martins & \\
Wesley Vieira da Silva & \\
\hline $\begin{array}{l}\text { Edileusa Godoi-de-Sousa; } \\
\text { Valdir Machado Valadão Jr. }\end{array}$ & \\
\hline Luiz Alex Silva Saraiva; & USP \\
Ronaldo Eurípedes das Mercês & UFU \\
\hline & UFMG \\
\hline
\end{tabular}

Fonte: Elaborada pelos autores.

$\mathrm{Na}$ Tabela 3 apresenta-se um percentual de 25\% das instituições dos autores. Analisadas no terceiro setor, concentram-se a Universidade Federal de Minas Gerais, seguida pela Universidade de São Paulo e pela Faculdade Paranaense sendo que as duas foram identificadas com $12 \%$ das instituições de ensino cada uma. Outros 18\% ficaram divididos igualmente entre as universidades UNICAMP e UFT, além de $6 \%$ representado pela PUCPR. Verifica-se que os demais $27 \%$ dessa análise foram divididos em percentagens iguais a $3 \%$ entre as universidades UFU, INIVALI, UFSC, IFMG, PUC-RIO, UFLA, FGV, FEA-USP E CEPEAD-MG.

É importante destacar que a UFMG possui um projeto de extensão dentro da universidade, que possibilita aos pesquisadores investigar mais sobre variados temas, incluindo terceiro setor. A FAPAR também possui pesquisadores voltados à questão de agregar conhecimentos, no entanto a FAPAR foi a única entre as instituições dos temas de Economia Solidária, Economia Social e Terceiro Setor a não apresentar em seu meio acadêmico uma incubadora. Podemos considerar que ela ocupa um papel importante, principalmente entre a comunidade paranaense, pois busca integrar o indivíduo com o propósito de capacitá-lo para 
assuntos ligados ao âmbito econômico e político da sociedade, que são ligados e envolvidos com o terceiro setor.

Outra instituição que ganhou destaque na análise do terceiro setor é a USP. Nessa Universidade compete identificar a Incubadora Tecnológica de Cooperativas Populares USP, cujo trabalho é voltado a alunos de graduação, pós-graduação e trabalhadores que atuam na área de cooperativismo, autogestão, economia solidária entre outras.

Essas incubadoras trabalham embasamentos teóricos para qualificar seus participantes, trazendo temas que direcionam bem-estar, cooperação, ONGs, ou seja, buscam integrar a sociedade em questões que todos deveríamos ter amplo conhecimento e opinião de reação. No entanto, é preciso projetos que buscam aflorar questões sociais e políticas buscando o bem de todos os indivíduos da cadeia.

Figura 1 - Palavras-chaves identificadas nas publicações sobre terceiro setor

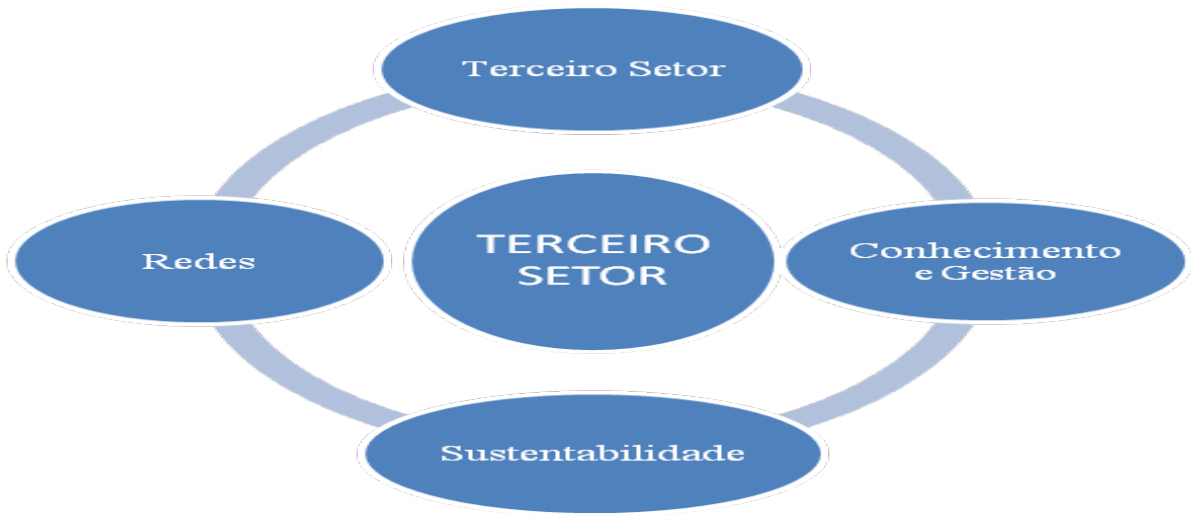

Fonte: Elaborada pelos autores.

Entre as palavras mais notadas, destacam-se a própria área, que é o terceiro setor, identificada sete vezes nos artigos, seguida pelas palavras Conhecimento e Gestão com cinco vezes, além das palavras Sustentabilidade (três vezes) e Redes (duas vezes). 


\section{CONSIDERAÇÕES FINAIS}

Este capítulo propôs-se a apresentar o resultado do levantamento bibliométrico da produção científica sobre terceiro setor do período de 2010 a 2016 na base de dados da Scientific Periodicals Electronic Library (SPELL).

Além de identificar os autores que mais se destacam entre os temas estudados, foi possível detectar a evolução da quantidade de autores por publicação sobre o tema. Nessa análise foram identificados quantos (quantidade) autores foram responsáveis pela construção do artigo, verificando-se que entre os 12 artigos estudados, a maior representatividade foi de artigos com dois autores.

Quando se busca realizar uma análise dos artigos que mais publicam sobre determinado tema é fundamental verificar qual periódico é mais identificado entre as publicações. No que diz respeito à análise, os periódicos com maior destaque foram a Revista de Administração Pública e a Revista da Administração da UNIMEP.

Outro ponto estudado foi verificar as instituições de ensino que mais publicam no tema sobre o Terceiro Setor, entre os anos de 2010 a 2016 no SPELL. Nessa análise podemos destacar a que mais apresentou autores foram à ordem das universidades, sendo a com maior destaque a Universidade Federal de Minas Gerais, seguida da Universidade Federal de Santa Maria e a Universidade Federal do Rio Grande do Sul, além da Universidade Federal do Tocantins, Universidade Estadual de Campinas, Universidade de Coimbra, Universidade Federal do Rio Grande do Norte e Universidade Federal de Santa Catarina.

No que diz respeito à instituição de ensino dos autores, as universidades destacadas possuem projetos que visam à pesquisa e extensão, assim como incubadoras, que acabam por obter destaque nessa investigação. Não se pode afirmar que o único ponto de algumas universidades apresentarem mais publicações está diretamente ligada ao fato de ter ou não uma incubadora; no entanto, podemos afirmar que as incubadoras são responsáveis pelo incentivo a pesquisas de determinados temas, o que se caracteriza como ponto-chave para observar que as universidades destacadas entre as instituições de ensino possuem incubadoras.

Observa-se, ainda, que a temática terceiro setor encontra-se presente no cotidiano dos indivíduos, mas não diretamente no dia a dia. Há assuntos interlaçados ao termo, como questões sociais, políticas e econômicas. Por isso, o estudo 
que deu origem a este capítulo obteve relevante papel, pois revelou o crescimento de pesquisas voltadas ao terceiro setor, oriundos, direta ou indiretamente, dos vários incentivos governamentais, as novas ONGs, podendo refletir, assim, uma gama cada vez maior de pesquisadores buscando compreender tal temática.

Há limitações quando se trabalha com apenas um tema de pesquisa, que, neste caso, apresentou baixa quantidade de publicações e confusão nas buscas na base de dados por palavras/ descritores ligados a qualquer questão social. Deixamos, portanto, uma breve referência sobre o tema, sugerindo que, para futuras pesquisas, se investiguem outras bases de dados, no intuito de ampliar o universo investigado e, consequentemente, a construção de novos conhecimentos.

\section{REFERENCIAS}

ALVES, Mário Aquino. Terceiro setor: as origens do conceito. ENANPADEncontro anual da Anpad, v. 26, 2002.

ARRUDA, Marcos. Socioeconomia solidária. A outra economia. Porto Alegre: Veraz editores, p. 232-241, 2003.

BENTO, Greici Diana. Contabilidade e Gestão no Terceiro Setor: Um Estudo Bibliométrico em Periódicos Nacionais. 2010. 77f. Monografia, Universidade Federal de Santa Catarina, Florianópolis.

BOTELHO, Louise de Lira Roedel et al. Universidades Empreendedoras: panorama dos estudos brasileiros sobre o tema. XIII Colóquio Internacional sobre Gestão Universitária nas Américas, 2013. v. 01. p. 01-15.

BRITO, Paulo Pessoa et al. A utilização dos demonstrativos contábeis como instrumento de apoio a gestão nas organizações não governamentais: um estudo de caso no estado do Ceará. Revista alcance, v. 15, n. 1, p. 61-80, 2008. CARVALHO, Jaqueline Elisa; CANÇADO, Airton. Gestão e Racionalidade: Análise da Metodologia de Incubação de Cooperativas Populares da ITCP/ NESol/UFT. In: CANÇADO, A. C.; CANÇADO, A. C. M. G. Incubação de cooperativas populares: metodologia dos indicadores de incubação. 2. ed. Palmas: Futura, 2009.

DA FONSECA, Edson Nery. Bibliografia estatística e bibliometria: uma reivindicação de prioridades. Ciência da Informação, v. 2, n. 1, 1973.

FALCONER, Andres Pablo. A promessa do Terceiro Setor. 1999. 
FERNANDES, Rubem César. O que é o terceiro setor? Revista do legislativo, Belo Horizonte, n. 18, p. 26-30, abr./jun. 1997.

FILANTROPIA. ORG. O que é o Terceiro Setor. Disponível em: http://www. filantropia.org/OqueeTerceiroSetor.htm. Acesso em: 22 mar. 2016.

FILOMENO, K. Mitos familiares e escolha profissional: uma visão sistêmica. São Paulo: Vetor, 1997.

GUERRA, Ana Carolina. Gestão das incubadoras tecnológicas de cooperativas populares: uma análise comparativa. Lavras: UFLA, 2008. GUIMARÃES, Gonçalo. Integrar cooperativas. São Paulo: Unitrabalho, 1999. FRANÇA FILHO, Genauto Carvalho de. Terceiro setor, economia social, economia solidária e economia popular: traçando fronteiras conceituais. Bahia Análise \& Dados, v. 12, n. 1, p. 9-19, 2002.

MACIAS-CHAPULA, Cesar A. O papel da informetria e da cienciometria e sua perspectiva nacional e internacional. Ciência da informação, v. 27, n. 2, p. 134-140, 1998.

PAES, José Eduardo Sabo. Fundações, associações e entidades de interesse social: aspectos jurídicos, administrativos, contábeis e tributários. 9. ed. Rio de Janeiro: Forense, 2003.

PEREIRA, José Roberto. Considerações metodológicas sobre o processo de incubação de cooperativas populares. In: CANÇADO, A. C.; PEREIRA, J. R.; SILVA JÚNIOR, J. T. Economia solidária, cooperativismo popular e autogestão: as experiências de Palmas/TO. Palmas: NESol/UFT, 2007. v. $1.320 \mathrm{p}$.

RAP. Revista de Administração Pública. Disponível em: http://www.scielo.br/ revistas/rap/pinstruc.htm. Acesso em: 30 set. 2016.

RAU. Revista de Administração da Unimep - Unimep Business Journal. Disponível em: http://www.raunimep.com.br/ojs/index.php/regen/index. Acesso em: 06 out. 2016.

RICHARDSON, Roberto Jarry. Pesquisa social: métodos e técnicas. São Paulo: Atlas, 1989. Estratégias para mudança. O Processo de estratégia. Porto Alegre: Bookman, p. 20, 2001.

SERVA, Maurício. O Estado e as ONGs: uma parceria complexa. Revista de Administração Pública, v. 31, n. 6, p. 41-54, 1997.

VERGARA, S. C. Projetos e relatórios de pesquisa em administração. 3. ed. São Paulo: Atlas, 2000. 